\title{
MEMORIAIS DE ESTUDANTES DA LICENCIATURA EM EDUCAÇÃO DO CAMPO: LETRAMENTOS E IDENTIDADES MATERNAS
}

\author{
MEMORIALS OF UNDERGRADUATE STUDENTS IN RURAL EDUCATION: \\ LITERACIES AND MATERNAL IDENTITIES
}

\author{
Silvia Naara da S. Pinto de Oliveira ${ }^{1}$
}

\begin{abstract}
Resumo: O objetivo deste artigo é descrever trechos narrativos que constroem identidades maternas em práticas de letramentos. A pesquisa analisa o gênero memorial escrito por estudantes da Licenciatura em Educação do Campo (LEdoC), identifica trechos em que as crenças no poder da escrita são manifestadas e reflete sobre a importância da figura materna para as estratégias de letramento. A pesquisa, de cunho qualitativo, foi realizada na Faculdade UnB Planaltina (FUP) com estudantes da disciplina Leitura e Produção de Textos I, ofertada durante o primeiro semestre de 2018. Como metodologia para a geração dos dados, o projeto contou com a observação participativa, a leitura e análise dos memoriais. A fundamentação teórica do trabalho abarca as áreas dos Letramentos Múltiplos (STREET, 2014; SOUSA et al., 2016), Gêneros discursivos (BAKHTIN, 1997) e Construção de Identidades (WOODWARD, 2000), entre outras perspectivas e autores/as.
\end{abstract}

Palavras-chave: Memorial. Letramento e Educação do Campo. Identidade materna.

Abstract: This paper aims to identify elements of maternal identities in literacy practices. The research analyzes memorial writings of undergraduate students of education at the Undergraduate Course in Rural Education (LEdoC) program at the University of Brasilia. It indicates excerpts were the student's belief on the positive changing power of writing is expressed and reflects the importance of the maternal figure in literacy. This is a research of qualitative nature and was developed at UnB's campus in the city of Planaltina (Faculdade UnB Planaltina - FUP) with students of the course Reading and Text Production I, offered during the first semester of 2018. As a methodology for data generation, the researcher observes the students' participation in class, and analyses their written memorials. The theoretical foundation of the work covers, among others, the areas of Multiple Literacies (STREET, 2014; SOUSA et $a l ., 2016)$, Speech Genres (BAKHTIN, 1997) and Identity Building (WOODWARD, 2000).

Keywords: Memories. Literacies and Rural Education. Maternal identities.

\section{Uma contextualização narrativa}

A maior sala de aula da FUP (Faculdade UnB Planaltina) estava lotada. A postura descontraída da maioria das pessoas caracterizava a aula de Letramento como um momento de aprendizado, de acolhimento e debates. Era uma das turmas do curso de Licenciatura em Educação do Campo (LEdoC), na aula que "ensina a ler os textos difíceis" e a escrever os fichamentos exigidos pela faculdade. A professora regente conversava com os/as educandos/as sobre as atividades da disciplina, como a escrita do memorial, por exemplo, e sobre o encerramento das aulas que ocorreria em poucos dias. Como integrante do projeto Laboratório de Múltiplos Letramentos ${ }^{2}$, o Labmult, a atividade naquele dia era a observação participativa e

\footnotetext{
${ }^{1}$ Universidade de Brasília, Brasília, DF, Brasil.

${ }^{2} \mathrm{O}$ projeto objetiva principalmente atender as necessidades comunicativas de educandos, professores, técnicos administrativos e funcionários terceirizados da FUP na perspectiva de aprimorar a norma "padrão" do português por
} 
auxílio aos/as educandos/as em possíveis dúvidas em leitura e escrita. Além de contribuir com o letramento acadêmico, o projeto, com início em abril de 2018, tem como um dos objetivos traçar o perfil acadêmico dos/as ingressos/as na LEdoC por meio de uma pesquisa etnodiscursiva orientada (questionário/diagnóstico). Para isso, os/as estudantes responderam a um diagnóstico de socioletramento (SOUSA, no prelo) que visava tanto conhecer a história de vida deles/as quanto compreender seu lugar social e traçar estratégias pedagógicas a fim de favorecer o letramento acadêmico. O diagnóstico de socioletramento foi realizado durante as aulas de Letramento, logo no início da etapa presencial dos/as estudantes na Universidade de Brasília.

O primeiro contato com os/as estudantes das turmas da LEdoC foi por meio dos memoriais escritos por eles/elas, como parte das atividades propostas pela professora regente, e que integravam o diagnóstico de socioletramento. Ao ler todos os memoriais, chamou minha atenção a referência à mãe como figura essencial no processo tanto de aquisição da leitura e da escrita quanto nas estratégias de aprimoramento das práticas de letramento. Foram lidos 61 textos, dos quais 14 faziam menção à mãe como personagem central participante desses processos.

Partindo do contexto da importância da interação entre as pessoas para o processo de aprendizagem (BORTONI-RICARDO, 2010), observei, por meio da leitura dos memoriais, que a figura materna assume o papel de agente de letramento para os/as estudantes da LEdoC, sendo que já havia verificado isso em diagnósticos de outras turmas. Assim, foi idealizado um projeto metodológico cujo objetivo principal é

- Descrever trechos de relatos autobiográficos que constroem a identidade materna em práticas de letramento de educandos/as de uma turma da Licenciatura e Educação do Campo no campus da Faculdade UnB Planaltina.

Os demais objetivos da pesquisa são:

- Analisar o gênero memorial escrito por educandos/as da LEdoC;

- Identificar trechos dos memoriais em que as crenças sobre o poder da escrita são manifestadas;

- Refletir sobre a importância da identidade materna para as estratégias de letramento.

A reflexão sobre os relatos autobiográficos e a construção da identidade materna partem dos seguintes questionamentos:

- Como os/as educandos/as da LEdoC relatam as ações maternas no processo de letramento?

- Quais as estratégias de letramento usadas pelas mães e relatadas pelos/as educandos/as da LEdoC?

- As práticas de letramento desenvolvidas pelas mães são essenciais à aquisição da leitura e da escrita?

As pesquisas que assumem a perspectiva qualitativa permitem interpretar o outro e as situações que nos cercam de maneira ontológica (DENZIN; LINCOLN, 2006), o que inclui a pesquisadora, ou o pesquisador, e as pessoas com as quais se dará o trabalho. Essas pessoas fazem parte de culturas e contextos situados. Dessa forma, ao elaborar as perguntas e os objetivos para a pesquisa, procurei traçar uma linha metodológica que alia a análise do discurso

meio de práticas de leitura e escrita, com foco em gêneros acadêmicos. Parte da geração de dados para a pesquisa sobre o protagonismo de egressas da LEdoC, tese de doutorado em desenvolvimento, acontece nesse projeto iniciado em 2018. 
às questões etnográficas. Segundo Magalhães et al. (2017), estender o olhar para além da análise textual do discurso revela contextos sociais relevantes para o projeto que temos em vista.

\section{2. $O$ contexto da pesquisa}

A pesquisa qualitativa se situa na tradição interpretativista, o que orienta a pesquisadora ou $o$ pesquisador a entrar no processo de pesquisa a partir de dentro de uma comunidade. Essa comunidade possui suas próprias práticas sociais e, ao participar socialmente das ações comunitárias, a pesquisadora ou o pesquisador podem observar diferentes aspectos dos indivíduos e interpretar dados vinculados aos seus objetivos de estudo. A pesquisa de campo oferece a oportunidade de analisar criticamente as práticas sociais, bem como interpretá-las à luz de aspectos teóricos concernentes ao contexto dos estudos. A pesquisa qualitativa parte do princípio de que vale a pena contar aos outros o que outros têm a dizer (DENZIN; LINCOLN, 2006), assim, a observação participativa, como estratégia de pesquisa, é eficaz para o contato com as pessoas na comunidade em que vivem. Entretanto, as estratégias podem ser diversificadas em outras técnicas como notas de campo, diários de pesquisa, vinhetas, o que forma a multiplicidade de gêneros discursivos como estratégias de pesquisa. Como observa Magalhães et al., 2017, p 120.

a mescla de gêneros discursivos nas notas de campo vão caracterizar a pesquisa etnográfico-discursiva. O relato etnográfico compõe-se de vários gêneros discursivos, formando uma cadeia de gêneros: notas divisórias (por assunto), observações gerais, esquemas, diários e cartas do campo.

Heath e Street (2008) contribuem com essas reflexões ao propor as notas conceituais como relevantes para a geração de dados. As notas são textos redigidos pela etnógrafa ou pelo etnógrafo dirigidos a si mesmos com observações específicas sobre o campo de pesquisa. Marcus (1986) aponta a mera descrição dos dados etnográficos como um dos desafios da etnografia contemporânea no mundo moderno. Segundo o autor, faz parte do trabalho etnográfico a interpretação dos dados numa perspectiva de reflexividade sobre o contexto sóciocultural que permeia a pesquisa. Assim, observar as aulas do componente curricular de Letramento e participar das atividades propostas nessas aulas influencia minha visão como pesquisadora, visto que também faço parte do grupo, embora numa perspectiva diferente das demais pessoas.

Transcrevo aqui um trecho de parte das notas conceituais que escrevi por ocasião de minha atuação na FUP:

Fup, 09 de abril de 2018.

Hoje fui pela primeira vez à Fup conhecer a turma X. Já os conhecia do memorial. A professora, logo no início das aulas de letramento, pediu que os/as educandos/as escrevessem um memorial após o questionário de sócioletramento. Li o questionário e os memoriais, a maioria deles. Alguns nomes e textos já haviam me marcado e estava bem curiosa para conhecê-los pessoalmente.

Com o objetivo de tentar compreender as experiências humanas por meio de narrativas, escolhi a observação participativa, as notas conceituais e diários de campo, além das análises textuais dos memoriais. A roda de conversas sobre o tema 'as mães como primeiras professoras', também está no planejamento intencional da pesquisa. Porém, como o curso da LEdoC mantém o sistema de alternância, os/as estudantes retornaram às suas comunidades antes que este projeto de pesquisa etnográfica fosse concluído. 
Para a melhor compreensão do contexto da pesquisa, faço uma síntese do que é a LEdoC, um curso específico para as pessoas que já atuam como docentes, ou em outras atividades educativas em comunidades camponesas, ou ainda que desejam obter a formação e atuar em escolas do campo. Os/as docentes formados/as por esse curso são licenciados/as em Educação do Campo e habilitado/as em Linguagens ou Ciências da Natureza ou Matemática, habilitação que será escolhida no início da licenciatura. O curso é organizado em etapas alternadas presenciais, equivalentes aos semestres nos cursos regulares, que são chamadas de Tempo Universidade (TU) e em etapas na comunidade, quando o/a estudante atua em seu grupo social de origem através de atividades de pesquisa e formação; esse período é chamado de Tempo Comunidade (TC) (PPP, 2018). As pessoas que ingressam na LEdoC são responsáveis por várias ações formativas em suas comunidades de origem e essas ações não estão restritas ao espaço e nem ao tempo acadêmico, ao contrário, os/as estudantes da LEdoC ampliam as vivências acadêmicas ao vincular a prática ao conhecimento teórico adquirido na universidade (SOUSA, MOLINA e ARAÚJO, 2016).

O segundo contato com as pessoas da turma da LEdoC, foi no início de abril, em 2018, quando participei da aula de letramento em colaboração com a professora regente. No memorial ${ }^{3}$, os/as estudantes deveriam relatar experiências de vida relacionadas ao contexto da leitura e da escrita. Foram esses relatos que revelaram a figura materna como agente de letramento.

Na pesquisa, exclui os textos que mencionavam o pai, as avós, as tias ou irmãos como agentes de letramento, embora esses familiares também sido bastante relatados nos memoriais. Praticamente todos os textos mencionam a importância da família no incentivo das práticas de leitura e de escrita.

Os memoriais são textos autobiográficos que recuperam parte das experiências dos/as estudantes quando crianças, ou jovens, na época em que foram alfabetizados. Por seguir uma sequência narrativa, é possível empregar a análise textual dos memorias dos demais gêneros narrativos, ou seja, podem ser descritos resumidamente como uma sucessão de eventos organizados numa ordem temporal; um sujeito protagonista, mesmo que haja mais personagens; uma ideia de progressão com um início, um meio e um fim; um conjunto de causas que sustentem os fatos narrados (a intriga). Os estudos dos gêneros discursivos trazem importantes contribuições à análise das narrativas. A tese de Bakhtin (1997) de que todas as atividades humanas estão relacionadas às ações linguísticas, nos remete aos vários enunciados, orais ou escritos, que permeiam nossa vida. Dessa forma, compreendemos que os enunciados refletem as diversas condições de intencionalidade dos discursos mediante as esferas de comunicação, que além de sua funcionalidade, refletem também condições específicas de tema, estilo e recursos lexicais empregados para a comunicação. Quando os/as estudantes da LEdoC redigiram os memoriais, tinham em vista cumprir uma tarefa solicitada para cumprir um requisito de aula. Todos os que entregaram o memorial alcançaram linguisticamente o objetivo de relatar suas experiências num texto narrativo progressivo. As narrativas são parte intrínseca do pensamento humano e de sua realidade, dessa forma, compreendemos e interpretamos o sentido da vida quando estudamos textos de sequências narrativas (MOTTA, 2012). Analisar as narrativas é interpretar as ações das pessoas, as relações sociais que as cercam e o mundo em que vivem. Assim, estudar as narrativas dos/as ledoquianos/as (estudantes da LEdoC) é tentar interpretar seu mundo através de um texto que revela o mundo individual. A descrição da mãe

\footnotetext{
${ }^{3}$ Os estudantes da LEdoC receberam a seguinte orientação para a escrita do memorial: É um texto escrito pelo próprio autor, ou por uma pessoa autorizada, que descreve e narra de forma oral ou escrita fatos da vida de uma pessoa. Existem diversas modalidades de memoriais e a estrutura linguística desse gênero textual é relativamente livre. O foco de interação está no leitor e em seu relato de vivências. Recomendamos que você escreva o texto em primeira pessoa; relate sua experiência de alfabetização e/ou experiências com a leitura na infância; relate outras experiências relacionadas à leitura e à escrita no contexto escolar (fundamental e médio); discorra sobre como são suas práticas de leitura e de escrita hoje.
} 
como participante essencial no processo de letramento dos/as estudantes quando crianças, revela a multiplicidade de identidades que essas mulheres assumem socialmente.

\section{Sobre identidade}

As transformações da vida moderna fazem com que assumamos diversas atividades correspondentes aos diversos papeis que desempenhamos em sociedade. Giddens (2002, p. 39) indica, inclusive, o monitoramento social sobre nossas ações a motivação para realizar ou não determinadas atividades:

As convenções sociais produzidas e reproduzidas em nossas atividades diárias são reflexivamente monitoradas pelo agente como parte do 'seguir em frente' nas diversas situações de nossas vidas. A consciência reflexiva nesse sentido é característica de toda ação humana, e é a condição específica daquela reflexividade institucional maciçamente desenvolvida como produto intrínseco da modernidade. Todos os homens monitoram continuamente as circunstâncias de suas atividades como parte do fazer o que fazem[...]

Faz parte de nossas reflexões pensar sobre as mudanças sociais que influenciam a vida das pessoas. A construção da identidade está intimamente vinculada às ações que realizamos e que são exigidas de nós. Por identidade compreendemos ser o conjunto de características próprias e exclusivas de um indivíduo, além dos produtos culturais, sociais e crenças pessoais. A construção da identidade está em constante adaptação, manifestando-se por meios discursivos (GIDDENS, 2002).

Woodard (2010) amplia a discussão, afirmando que as identidades são muitas e passíveis de transformações nos diversos contextos sociais, sendo vividas também nos sistemas simbólicos dos quis fazemos parte e que (re)significam nossa vida. Assim, mencionar a mãe como alguém participante dos processos de letramento é destacar a figura materna e as ações que seus/suas filhos/as consideram como relevantes para os processos de leitura e de escrita. Embora o papel de ensinar os/as filhos/as seja visto em nossa sociedade como uma atividade intrínseca da função materna (VIEIRA 2005). Os memoriais revelam que as mães assumem também outras identidades. As mulheres não são apenas mães e mesmo as que são mães dificilmente resumem suas atividades pessoais e sua esfera de atuação na sociedade unicamente à esfera materna. Os/as ledoquianos/as observam as ações sociais das mães e relatam nos memoriais essas transformações:

$\mathrm{Ana}^{4}, 21$ anos, de Café-sem-troco - DF:

Aprendi o alfabeto com uma amiga da minha mãe, que minha mãe pagou ela para ela me ensinar a ler e a escrever também.

Ana relata no memorial ter sido criada pela avó, a quem chama de mãe. Sobre a escolaridade dos pais, Ana menciona apenas a avó, que é analfabeta, mas que contratou uma amiga para ensinar a neta a ler. A identidade materna de provedora material é descrita no relato: por falta do conhecimento escolarizado, a mãe supre a necessidade remunerando outra pessoa habilitada.

Outro relato autobiográfico que revela a identidade materna em outros aspectos é o de

Evelyn $^{3}, 34$ anos, de Unaí, MG:

Minha mãe começou a se envolver na luta e a militar no MST.

\footnotetext{
${ }^{4}$ Com a finalidade de garantir o anonimato das pessoas participantes da pesquisa optamos por usar nomes fictícios.
} 
Segundo Evelyn, após o envolvimento de sua mãe como militante do Movimento Sem Terra, surgiu a consciência da importância da aquisição da leitura e da escrita.

\section{A análise de trechos relevantes para a pesquisa}

As práticas de letramento são práticas socioculturais de leitura e de escrita que perpassam o cognitivo de modo que as pessoas recorrem a essas práticas de forma a representar suas atividades e, numa espécie de mão dupla, essas práticas também moldam o cotidiano social. Segundo Sousa (2016), ler e escrever têm diferentes propósitos, dependendo do contexto em que essas práticas serão empregadas.

O letramento, como uma cultura, se constitui de práticas sociais em que as pessoas se valem de textos escritos para registrar suas memórias, acordos, expandir e reinventar o conhecimento em todas as dimensões históricas, científicas e sociais. Esse fenômeno ocorre em diferentes domínios sociais: universidade, escola, lar, igreja, trabalho e lazer. (SOUSA, 2016, p. 79)

Para as análises, foram selecionados seis memoriais dos quatorze que mencionam as mães como figuras importantes para suas experiências com a leitura e com a escrita. $\mathrm{O}$ critério empregado para a seleção foi a relação direta da figura materna com as práticas de letramento dirigidas ao estudante de licenciatura. Assim, para atender aos objetivos do trabalho, a reflexão será sobre as seguintes abordagens discursivas:

a. O amor da mãe pela leitura e sua influência na família;

b. A crítica ao sistema educacional e as estratégias de letramento usadas pelas mães para suprir as citadas deficiências educacionais.

A grande parte dos memoriais analisados foi escrita por mulheres; apenas um deles foi escrito por um estudante; sendo de 20 anos a idade média das autoras e do autor dos memoriais. Com o objetivo de preservar a identidade pessoal dos participantes da pesquisa, foram usados pseudônimos para identificar os trechos dos textos. Os trechos transcritos são fiéis às escritas dos estudantes, ou seja, foi mantida a variação linguística empregada nos relatos memoriais.

$\mathrm{Na}$ primeira abordagem, os relatos que revelam o amor das mães pela leitura ou pelos livros, são expostos trechos dos memoriais em que as pessoas relatam a influência materna pelo gosto pela leitura, atividade essa que perpassa aos filhos e às filhas:

1. Luciana, 22 anos, de Teresina de Goiás, GO:

Minha experiência com a leitura vem de berço, minha mãe adora ler e repasso isso para mim e meus irmãos.

Luciana, inicia o memorial narrando suas lembranças mais remotas, da primeira infância, quando já via a mãe lendo, um hábito que, segundo a estudante, foi passado aos filhos. Sobre a escolaridade dos pais, Luciana conta que a mãe chegou até o ensino superior, também é discente da LEdoC; o pai possui o ensino fundamental. As preferências de Luciana são ir aos festejos da comunidade e ouvir músicas como rap, reggae, funk e sertanejo. Ela diz não gostar de poesia e afirma que aprendeu a ler e a escrever apenas o básico no período em que frequentou a educação básica. O memorial de Luciana é curto, sem muitas informações além das mencionadas. Sobre as atividades de letramento que desenvolve hoje, os relatos da estudante estão resumidos ao 
ensino de leitura para o filho de quatro anos, e não menciona o processo seletivo para o ingresso no curso e nem o próprio curso é mencionado como atividade que requer leitura e escrita.

2. Mateus, 18 anos, de Flores, GO:

Minha mãe é apaixonada por ler. Ela gosta muito de ler livros, um tempo atrás ela insistiu bastante e eu comecei a ler livros de histórias só que com o passar do tempo parei, hoje gosto de ler livros de tirinhas e leio livros da faculdade.

Mateus, um dos mais jovens do grupo, conta que mora num assentamento na cidade de Flores, no estado do Goiás. Seu pai estudou até a $3^{\mathrm{a}}$ série $\left(2^{\circ}\right.$ ano) do ensino fundamental e sua mãe começou a $7^{\mathrm{a}}$ série ( $8^{\circ}$ ano). Mateus conta da paixão de sua mãe pela leitura e a influência materna foi um fator decisivo para aquisição dos processos de letramento em que Mateus está envolvido. Ele menciona os trabalhos da faculdade, as mensagens que envia no celular e as interações em redes sociais como as principais atividades de letramento de que participa.

Brian Street (2014, p. 17) levanta a perspectiva do letramento como uma "prática ideológica, envolvida em relações de poder e incrustada em significados e práticas culturais específicos". Ou seja, as condições culturais afetam o significado das práticas comunicativas, assim, o letramento deixa de ser visto apenas como artefato de comunicação para ser também um comportamento social. Ainda segundo Street (2014), a escola oferece mais procedimentos de letramento escolar enquanto que as famílias podem oportunizar outras formas de letramentos inclusive de práticas consideradas desvalorizadas pela pedagogia moderna. A repetição sistemática, a coerção ao estudo e as punições são práticas descritas nos memoriais como recorrentes no contexto familiar dos/as ledoquianos/as. Assim, a segunda abordagem discursiva tem a ver com a crítica ao sistema educacional e as ações realizadas pelas mães na tentativa de suprir as carências acadêmicas dos/as filhos/as. Ao perceber as dificuldades do contexto de ensino e aprendizagem, os/as estudantes relatam que as mães criaram estratégias para ensinar ou para reforçar os processos pedagógicos da escola em casa.

3. Mariana, 24 anos, de Flores de Goiás, GO:

Minha alfabetização foi aos 7 anos de idade, eu costumo dizer que foi $35 \%$ na escola e 65\% em casa, tendo a minha mãe como professora. Quando eu chegava da escola, logo após o almoço, ela nos colocava para sentar na mesa, eu e o meu irmão e refazer todas as tarefas que já havíamos feito na escola, e foi ali na prática repetitiva que aprendemos a ler e escrever.

O relato de Mariana é detalhado estatisticamente ao creditar o sucesso na alfabetização às práticas de sua mãe, em casa. Mariana mora no Assentamento P. A. São Vicente, em Flores de Goiás, estuda e cuida da família, mas até pouco tempo atrás militava no Movimento Sem Terra (MST), movimento do qual se afastou para dedicar-se integralmente ao curso da LEdoC e aos cuidados do filho pequeno. No memorial, Mariana descreve as ações de sua mãe que consistiam basicamente na repetição do que já havia sido feito na escola: sentar à mesa após o almoço e refazer todas as tarefas passadas pela professora na escola. Mariana acredita que essas práticas repetitivas garantiram o letramento escolar. Mariana acrescenta no memorial que via a mãe lendo constantemente, o que a incentivou a ler também:

Eu sempre tive o incentivo da minha mãe para ler, na minha casa tinha muitos livros pois a minha mãe lia bastante. 
Mariana afirma que atualmente suas práticas de leitura e escrita estão restritas aos trabalhos da faculdade.

Um outro exemplo de crítica ao ensino e interferência materna no processo de letramento é o relato de Cátia, de 18 anos, moradora de Alto Paraíso de Goiás.

4. Eu, $C$, relato de quando minha mãe me ensinou a fazer meu nome completo com muito amor e paciência, porque a professora não ensinava direito, pois por falta de não saber ler com 7 anos minha mãe foi na escola para falar com a professora pra me reprovar, assim repetindo a terceira série até saber a ler e escrever.

Embora tenha sido aprovada regularmente no processo seletivo para a LEdoC, a escrita, especificamente do memorial, de Cátia se mostrou insuficiente para a expectativa de aprendizagem do componente curricular Letramento. Pelo seu relato, é possível perceber que a mãe usou a estratégia do reforço repetitivo, em casa, até que Cátia escrevesse o nome completo. Entretanto, não satisfeita com a aquisição de leitura e escrita na escola, a mãe interferiu no processo de aprovação da filha até que essa soubesse ler e escrever de forma que a mãe considerasse eficaz. Sobre a escolaridade dos pais, Cátia menciona apenas a mãe, também egressa da LEdoC, do curso de Linguagens, mas não disse se sua mãe já tinha concluído o curso quando esses fatos aconteceram. Cátia afirma ser lavradora de profissão, mas trabalhar como diarista na cidade. As atividades de letramento que realiza atualmente são destinadas às aulas da LEdoC e interação nas redes sociais.

Outras estudantes também descrevem as estratégias maternas de leitura e de escrita em casa:

5. Carla, 22 anos, de Cavalcante, GO:

Ela me colocava para lê, soletrar, formar palavras comprava caderno pra mim.

6. Yasmin, 24 anos, de Cavalcante, GO:

Minha mãe foi minha primeira professora ela é uma das pessoas que me ajudou muito com meus estudos. Ela passava muitos trabalhos para fazer final de semana, chegando no sábado e domingo eu não poderia sair pra brincar e nem passear antes de fazer os trabalhos. Minha mãe sempre falava se não passar de ano apanha.

Carla e Yasmin, moradoras de Cavalcante, enumeram as ações maternas que reforçam o processo escolar em atividades realizadas em casa. As punições por não estudar ou não obter o sucesso esperado pelos pais também são relatadas. Por meio das narrativas das estudantes, é possível perceber que o letramento escolar é muito valorizado no contexto familiar. A crença no poder da escrita traz a reflexão sobre o poder de status e ascensão social para quem é hábil na leitura e na escrita, algo almejado pelas mães para seus/suas filhos/as. A maioria dos/as ledoquianos/as vêm de comunidades com pouca oportunidade de letramento e muitos/as estudantes precisam sair de suas localidades rurais para concluir os estudos básicos. Faltam escolas no campo mas não falta a consciência de que é preciso saber ler e escrever bem para compreender o mundo de hoje.

\section{Considerações}

As experiências narradas pelos/as estudantes da LEdoC situam a perspectiva interpretativista de pesquisa porque os memoriais revelam aspectos da vida dos/as estudantes que não seriam apresentados se não fossem desse modo. Magalhães et al. (2017, p. 30) afirma que por meio da pesquisa qualitativa 
é possível examinar uma grande variedade de aspectos do processo social, como o tecido social da vida diária, o significado das experiências e o imaginário dos participantes da pesquisa, a forma como se articulam os processos sociais, as instituições, os discursos e as relações sociais e os significados que produzem.

As pessoas falam do que é importante para elas e se a maioria dos/as estudantes menciona a figura materna como alguém que fortaleceu os processos de letramentos, é preciso considerar essas práticas como relevantes para o contexto da LEdoC. Os memoriais são textos que revelam aspectos da vida dos/as ledoquianos/as e de suas práticas de letramento que ampliam a perspectiva social e acadêmica sobre esses/as estudantes. O curso, por ser considerado um curso de inclusão, tem a possibilidade de refletir sobre as formas de acolhimento de seus/suas ingressos/as e suas experiências de vida como meios de aumentar tanto a adesão ao curso como garantir a permanência desses/as educandos/as na universidade pública.

\section{Referências}

BAKHTIN, M. Estética da criação verbal. São Paulo: Martins Fontes, 1997.

BORTONI-RICARDO, S. M.; MACHADO, V. R.; CASTANHEIRA, S. F. Formação do professor como agente letrador. São Paulo: Contexto, 2010.

DENZIN, N. K., LINCOLN, Y. O planejamento na pesquisa qualitativa: teorias e abordagens. 2. ed. Porto Alegre: Artmed, 2006.

FREIRE, P. A importância do ato de ler: em três artigos que se completam. São Paulo: Cortez, 2009.

HEATH, S. B., STREET, B. On etnography: approaches to language and literacy research. Nova York: Teachers College Press, 2008.

MAGAlHÃES, I; MARTINS, A. R.; RESENDE, V. M. Análise de Discurso Crítica: um método de pesquisa qualitativa. Brasília: Editora da Universidade de Brasília, 2017.

MARCUS. G. Contemporary problems of ethnography in the modern world systems. In: CLIFFORD, J.; MARCUS, G. Writing culture: the poetics and politicsof ethnography. University of California Press: London, 1986.

MOTTA, L. G. Por que estudar narrativas? In: MOTA, C. L. et al. (Org.). Narrativas midiáticas. Florianópolis: Insular, 2012.

ROJO, R. Letramentos múltiplos, escola e inclusão social. São Paulo: Parábola Editorial, 2009.

SOUSA, R. Socioletramento e formação de professores para diversidade étnica. Universidade de Brasília, no prelo.

SOUSA, R. Letramentos na licenciatura em educação do campo: transitando no contexto acadêmico. In: ARAÚJO, J. (Org.). Gêneros e letramentos em múltiplas esferas de atividade. Campinas: Pontes Editores, 2016. 
SOUSA, R.; MOLINA, M.; ARAÚJO, A. C. (Org.). Letramentos múltiplos e Interdisciplinaridade na Licenciatura em Educação do Campo. Brasília: Decanato de Extensão/UnB, 2016.

STREET, B. Letramentos sociais: abordagens críticas do letramento no desenvolvimento, na etnografia e na educação. São Paulo: Parábola Editorial, 2014.

UNIVERSIDADE DE BRASÍLIA. Faculdade UnB Planaltina - FUP. Projeto Político Pedagógico: Curso de Graduação em Licenciatura em Educação do Campo. Brasília-DF, 2018.

VIEIRA, J. A. A identidade da mulher na modernidade. DELTA, 2005, v. 21, n. espec., p. 207-238.

WOODWARD, K. in SILVA, T. (Org.); HALL, S; WOODWARD, K. Identidade e diferença: a perspectiva dos estudos culturais. Petrópolis: editora Vozes, 2000.

\section{Sobre a autora}

Silvia Naara da S. Pinto de Oliveira é graduada em Letras Português, Inglês e Literaturas (Universidade Federal de Mato Grosso do Sul), tem Mestrado em Linguística (Universidade de Brasília) e doutoranda em Linguística (Universidade de Brasília). É professora colaboradora da Universidade de Brasília. Tem experiência na área de Letramento, Gêneros Discursivos e Sociolinguística educacional com pesquisa nos seguintes temas: Letramento e a redação do Enem; A importância do letramento para as egressas do curso de Licenciatura em Educação do Campo. É membro do grupo de pesquisas Soleduc: (Sócio)Linguística Letramento Múltiplos e Educação.

E-mail: silvia.naara@hotmail.com. 